\title{
Profile of Patients Admitted to an Intensive Care Unit of a University Hospital
}

\author{
Mendonça $\mathrm{AE}^{1 *}$, Mariano AV2, Souza Júnior BS², Moura LA², Souza \\ Júnior BS², Ferreira DR ${ }^{1}$, Silva JC1, Ferreira TC1, Medeiros RA², \\ Oliveira $\mathrm{PM}^{2}$ and Xavier Nobre TT ${ }^{1}$ \\ ${ }^{1}$ Department of Nursing, Federal University, Brazil \\ ${ }^{2}$ University Hospital Onofre Lopes, Brazil
}

Research Article

Volume 3 Issue 1

Received Date: January 02, 2019

Published Date: February 01, 2019

DOI: $10.23880 /$ nhij-16000173

*Corresponding author: Ana Elza Oliveira de Mendonça, Federal University of Rio Grande do Norte, Rua Coronel Milton Freire, 2821, Capim Macio, Natal - RN, CEP 59078310, Brazil, Tel: (84)999841088; Email: anaelzaufrn@gmail.com

\section{Abstract}

Objective: trait of the profile of patients admitted to an intensive care unit of a university hospital.

Method: descriptive, cross-sectional study with retrospective data collection and quantitative approach, performed at a teaching hospital in the Northeast of Brazil. The data of the 247 participants were collected in an own form, and analyzed through descriptive statistics.

Results: the results showed that the studied population was predominantly composed of male elderly patients from the surgical center, and the admission diagnosis was predominant in the specialty of cardiology, with criterion of priority 2. The most frequent residence time was 1 to 2 Days, with a favorable clinical outcome due to the majority having been discharged from the ICU and the readmissions index was small during the analyzed period.

Conclusions: the knowledge of the profile of the patients admitted to the ICU allows improving health care planning and organization of the work process. It can provide the quality of care offered by establishing criteria for admission and rational use of the beds, minimizing patient exposure to unnecessary risks, non-programmed rehospitalization, mortality and other relevant indices for the assessment of health care in care the critical patient.

Keywords: Critical Care; Intensive Care Units; Patient Admission; Health Profile; Nursing

Abbreviations: ICUs: Intensive Care Units; CNCD: Chronic Non-communicable Diseases; UFRN: Federal University of Rio Grande do Norte.

\section{Introduction}

Intensive Care Units (ICUs) emerged in 1950 and since then have become recognized as spaces suitable for the treatment of severely ill people, allowing the prolongation of the life expectancy of acute and chronic patients considered as recoverable. This recognition was due to the use of technologies for constant monitoring, diagnostic methods and innovative therapies, as well as specialized human resources, that is, continuous observation and assistance of multidisciplinary health teams [1-8]. 


\section{Nursing \& Healthcare International Journal}

Throughout the world, there is a growing need for scientific evolution and technological development for the treatment of critical patients, which has enabled not only survival, but also an increase in the life expectancy of people with Chronic Noncommunicable Diseases (CNCD). This aspect has a unique epidemiological importance, since the demand for intensive care is more frequent in these individuals when compared to the general population $[3,9-11]$.

In developing countries, such as Brazil, actions to promote and prevent health problems are a huge challenge for healthcare professionals and managers, since there is a shortage of financial and human resources. The absence and/or inefficiency of these actions contribute to sickness, chronification and aggravation of diseases of different etiologies. Another factor that contributes to this phenomenon is the dizzying growth of the number of elderly poeple, resulting from the change in the epidemiological profile and the increase in life expectancy $[3,6,10,12,13]$.

On the other hand, there is a huge disproportion between supply and demand for beds for hospitalization, especially in ICU. It is worth noting that the lack of beds justifies the use and compliance of admission criteria by health professionals, as well as the use of protocols for evaluation and adoption of evidence-based conducts, aiming to standardize and improve the quality of care and patient safety $[3-6,11,14,15]$.

In Brazil, Ministerial Ordinance No. 1.101/2002, of June 12,2002 , estimates the need for hospital beds of 2.5 to 3 beds per 1,000 inhabitants and ICU beds are calculated from $4 \%$ to $10 \%$ of total hospital beds, which corresponds to an index of one to three ICU beds per 10,000 inhabitants. In all, Brazil has 40,960 thousand ICU beds, half of which are available to the Brazilian Health System (SUS), which potentially serves 204 million Brazilians, and the other half is reserved for private or supplementary health, responsible for approximately $25 \%$ of the population. SUS has 0.95 ICU beds for each group of 10,000 inhabitants, while the private network has 4.5 beds, which represents almost five times the supply of the public network. The number of beds in the SUS is insufficient to meet the growing demand, so patients without access to beds have gone to courts to obtain an ICU bed on judicial demand, further increasing government spending $[3,16,17]$.

Considering the importance of this topic, knowing the characteristics of the patients that need ICU stay becomes relevant to professionals and managers of health services, especially those who work in public health institutions agreed to SUS, with the intention of directing their actions to the real needs of the patients and contribute to improve the quality of care $[4,5,8]$.

The knowledge of epidemiological data on the morbidity and mortality of patients in a health unit makes it possible to choose and implement strategies aimed at improving health care. The incorporation of new technologies, training and qualification of human resources and the structural adequacy of services must be planned and adequate to the demographic and morbidity and mortality characteristics of the population that needs its services [4].

In light of the foregoing, the purpose of this study was to describe the profile of patients admitted to a general ICU of a university hospital.

\section{Methods}

This is a descriptive, cross-sectional study with retrospective data collection and quantitative approach, developed in the ICU of a university hospital, located in Natal/Rio Grande do Norte (RN). This unit has 16 beds for the hospitalization of critically ill patients in various specialties.

The study population consisted of 254 patients admitted in the period covered by the data collection, selected by convenience and consecutively, in which 247 patients of both sexes, hospitalized in the ICU, were included in the period from August to October 2016. One patient was excluded due to the need for a long stay in that sector, which made it impossible to obtain the data referring to the clinical outcome; other five patients were excluded because were aged less than 18 years and one due to insufficient recording of the items in the data collection instrument.

For collecting data, researchers developed a form containing closed questions, referring to the following variables: sex; age; specialty of admission diagnosis; length of hospital stay; unit of origin and group of admission priority. A pre-test was performed with 10 patients to evaluate the applicability of the instrument. Since there was no need for changes, these patients were included in the study. The instrument was completed in two moments, the first after the admission and the second on the occasion of discharge from the ICU or death. 


\section{Nursing \& Healthcare International Journal}

Data collection was performed by five researchers, of whom four were nursing students enrolled in the seventh and eighth semesters of the Nursing undergraduate course of the Federal University of Rio Grande do Norte (UFRN) and one was a nurse attending the adult intensive care residency program. The training of the researchers was initially carried out in a group through the presentation of the project and simulated filling of the data collection form and concluded with the individual follow-up in the service in the first days of the collection.

Data analysis was preceded by typing the data in a spreadsheet-format database of the Microsoft Office Excel 2013 program, which were analyzed by means of descriptive statistics and presented in a table.

The research project was previously submitted to the Research Ethics Committee of the institution, which obtained a favorable opinion under the number 030473/2016 and CAAE 55129716.5.0000.5292. The study followed all the recommendations of Resolution 466/12 for research involving human subjects [18].

\section{Results}

Of the 247 patients that constituted the population admitted to the ICU in the period from August to October 2016, 55.87\% were male and $44.13 \%$ female. As for age, the highest frequency observed was of individuals aged 60 years or over $(55.87 \%)$, with a mean of 59.66 , DP \pm 14.73 and variation of 20 to 93 years.

When analyzing the origin of the patients, the majority came from the surgical center (44.53\%), and the cardiology $(38.46 \%)$ was the most frequent specialty among the diagnoses that motivated admission. The length of stay in ICU varied from 1 to 5 days, however, the most frequent interval was 1 to 2 days (55.87\%), with a mean of 2.63 (SD 0.92). The most frequent clinical outcome was discharge from the unit $(83.00 \%)$, followed by deaths $(17.00 \%)$, and the demand for beds for rehospitalization corresponded to $6.88 \%$.

In Table 1 below, the data obtained from the patients admitted to the ICU were presented in absolute numbers and percentages, as collected for the construction of the profile.

\begin{tabular}{|c|c|c|}
\hline Variable & n 247 & $100 \%$ \\
\hline \multicolumn{3}{|c|}{ Sex } \\
\hline Male & 138 & 55.87 \\
\hline Female & 109 & 44.13 \\
\hline \multicolumn{3}{|c|}{ Age } \\
\hline$>60$ years & 138 & 55.87 \\
\hline 40 to 59 years & 86 & 34.82 \\
\hline 18 to 39 years & 23 & 9.31 \\
\hline \multicolumn{3}{|c|}{ Origin } \\
\hline Surgical Center & 110 & 44.53 \\
\hline Hemodynamics & 81 & 32.79 \\
\hline Nursery/Infirmary & 45 & 18.22 \\
\hline Another hospital institution & 11 & 4.46 \\
\hline \multicolumn{3}{|c|}{$\begin{array}{ll}\text { Specialty } \\
\end{array}$} \\
\hline Cardiology & 95 & 38.46 \\
\hline Gastroenterology & 40 & 16.19 \\
\hline Oncology & 30 & 12.15 \\
\hline Neurology & 16 & 6.48 \\
\hline Nephrology & 15 & 6.07 \\
\hline Pneumology & 13 & 5.26 \\
\hline Infectology & 14 & 5.67 \\
\hline Vascular & 13 & 5.26 \\
\hline Hepatology & 10 & 4.05 \\
\hline Dermatology & 1 & 0.4 \\
\hline \multicolumn{3}{|c|}{ Length of hospital stay } \\
\hline$<24$ hours & 5 & 2.02 \\
\hline
\end{tabular}




\section{Nursing \& Healthcare International Journal}

\begin{tabular}{|c|c|c|}
\hline 1 to 2 days & 138 & 55.87 \\
\hline 3 to 7 days & 66 & 26.72 \\
\hline 8 to 15 days & 22 & 8.91 \\
\hline$>$ 16 days & 16 & 6.48 \\
\hline \multicolumn{2}{|c|}{ Outcome } \\
\hline Discharge & 205 & 83 \\
\hline Death & 42 & 17 \\
\hline Re-hospitalization & 16 & 6.88 \\
\hline Admission priority criteria* \\
\hline Priority 2 & 136 & 55.06 \\
\hline Priority 1 & 104 & 42.11 \\
\hline Priority 3 & 3 & 1.21 \\
\hline Priority 4 & 4 & 1.62 \\
\hline
\end{tabular}

Table 1: Characteristics of the total sample (percentages).

(*)Priority 1 - severe, unstable patient requiring intensive monitoring and treatment that cannot be obtained outside the ICU; Priority 2 - patients requiring invasive monitoring and who may require immediate intervention; Priority 3 - severe, unstable patients with reduced chances of recovery due to the underlying disease or the nature of the acute problem; Priority 4 - patients who showed little or no benefit with ICU admission [14].

\section{Discussion}

Results show that, of the total number of patients analyzed $(\mathrm{n}=247)$, the male sex, with $138(55.87 \%)$, presented a predominance in relation to the females, with 109 (44.13\%). The distribution of patients in relation to sex was similar to that observed by Melo, et al. [4] in a retrospective study carried out in an ICU of a public hospital in Fortaleza. As already seen in other studies, it is in agreement with most of the researched literature $[2,4,7,8,11,13,15]$ also evidencing that men present a higher frequency in the number of hospitalizations, in general admissions and consequently in the ICUs, because they make less use of primary and secondary care services when compared to the female sex [10].

Elderly patients, that is, those above 60 years, were responsible for the largest portion of ICU admissions, with $55.87 \%$. This definition was based on the criterion used by the Statute of the Elderly [19]. It was followed by the age group of 40 to 59 years, with $34.82 \%$, and 18 to 39 years, with $9.31 \%$.

According to Schein [13] the elderly are responsible for $42 \%$ to $52 \%$ of ICU admissions, and the expenses correspond to $60 \%$ of the available daily budget. Veras [12] states that developing countries have been the subject of discussions in the areas of health planning and policies, and Brazilian statistical projections indicate that the elderly population will reach 32 million by 2020 .
In view of this, the high age range observed in patients admitted to the ICU can be justified by the aging process itself and also by the greater probability of developing chronic diseases, the vulnerability to physiological changes and to invasive procedures, which imply higher costs, longer duration of treatment and slower recovery $[2,3,8,10,12,15]$.

Regarding the unit of origin, most patients came from the surgical center, with 44.53\%, followed by hemodynamics, with $32.79 \%$. The others came from other units in the institution, as nursery, with $18.22 \%$. In addition, $4.46 \%$ came from other institutions in the municipality and other cities in the region.

Investigation on the distribution of patients by specialty presented as diagnoses that led to ICU admission identified cardiology, with $38.46 \%$, as the main cause, followed by gastroenterology, with $16.19 \%$, oncology (12.15\%), neurology (6.48\%), nephrology (6.07\%), infectology (5.67\%), also in pulmonology and vascular disease, with $5.26 \%$ in each, hepatology (4.05\%), and dermatology, with $0.40 \%$. It should be emphasized that the institution that constituted the study scenario is a reference in cardiac urgency, in which people with cardiovascular disorder with open demand are admitted to all hospitals and municipalities in the state, which may explain the high percentage of hospitalizations for this specialty in the investigated ICU. This finding corroborates that found in the literature $[3,6,10,13,15]$. 


\section{Nursing \& Healthcare International Journal}

Regarding the length of hospital stay, 138 (55.87\%) patients were hospitalized at the unit for a period of 1 to 2 days, corroborating with the Brazilian ICU census, whose mean is of 1 to 6 days [7,10]. A total of $66(26.72 \%)$ patients stayed in the ICU between 3 to 7 days, $22(8.91 \%)$ patients stayed 8 to 15 days and $16(6.48 \%)$ patients stayed for 16 days or more. Another 5 (2.02\%) patients remained hospitalized for less than 24 hours and had a very significant death rate, of which $4(80 \%)$ died. The greatest length of stay recorded was 42 days. There is no consensus in the literature regarding the definition of how many days of ICU stay are necessary to characterize a prolonged hospitalization [7]. Bezerra [3] says that it is important to emphasize that ICU stay should last the time necessary to solve the acute situation that led to hospitalization, as soon as possible to reduce the risk for infections, complications, mortality and costs.

Regarding the clinical outcome, the data showed that $205(83.00 \%)$ admitted patients were discharged from ICU, being transferred to other units of the institution and $42(17.00 \%)$ died. The mortality rate of this study is below the mortality rates accepted in the Brazilian ICUs, which varies between 34 and $40.5 \%$, as well as worldwide rates, ranging from $18.5 \%$ to $32 \%$ [1].

When analyzing the etiology of the diseases of patients who died, it was observed that the cardiovascular [13] and infectious complications $[8,11]$ were the most frequent causes, followed by impairment of the pulmonary $[8,13,17]$ and gastric system [17].

In the study carried out by Borges [20], hospital readmissions are a frequent problem in health institutions because they represent a burden on the health system, as well as discomfort to the patient and their families, and is considered an important indicator of quality of care because it reflects the impact of hospital care after discharge. It also brings us to the fact that international studies have identified hospital readmission rates ranging from $0.47 \%$ to $25.4 \%$, depending on the demographic characteristics and time of analysis between hospitalization and hospital readmission. On readmission, patients present worsening of the initial condition, thus increasing morbidity and mortality, hospital stay time and financial costs [15].

Comparatively, the incidence of hospital readmission in the adult population of the institution studied is in agreement with the literature, with a rate of $6.88 \%$ [16]. Of these, $56.25 \%$ died.
Due to the complexity and specificity of ICU with specialized human resources, technological instruments, high cost and limited number of beds, which are sometimes very scarce, it is necessary to define admission criteria in order to benefit the patient and optimize resources. The American Society of Intensive Care has developed criteria for vacancy priorities for admission to ICU, in which four priorities were divided according to the severity of the case. Priority 1 is given to severe and unstable patient requiring intensive monitoring and treatment that cannot be obtained outside the ICU; priority 2 is regarding patients requiring invasive monitoring and who may require immediate intervention; priority 3 encompasses severe and unstable patients with reduced chances of recovery due to the underlying disease or the nature of the acute problem and; priority 4 refers to patients who had previously little or no benefit from ICU admission [14].

The results found in this study are similar to those of Caldeira, et al. [14]. In the present study, priority 2 was predominant with $136(55.06 \%)$ patients, followed by priority 1 with 104 (42.11\%), who probably had more benefits with ICU treatment; priority 4 with 4 patients $(1.62 \%)$ and; priority 3 with 3 (1.21\%) patients, presenting higher mortality than priority 1 and 2 , suggesting that priority groups 1 and 2 have greater benefits in ICU admission than priority groups 3 and 4 .

\section{Conclusion}

The profile of patients admitted to the general adult ICU of the university hospital studied was composed of elderly male patients coming from the surgical center with cardiology as the admission specialty. The hospitalization time of 1 to 2 days, the clinical outcome with discharge from ICU and the priority group 2 were the most frequent. Few patients required to be readmitted.

It is hoped that the results of this study can contribute to the knowledge of the reality of admissions and assisted clientele, allowing planning the health care process, aiming to improve the quality of care offered to critical patients and establishing criteria for admission. This might provide the rational use of beds and faster recovery of the patient by minimizing their exposure to unnecessary risks, unscheduled readmission, mortality, and other relevant indices for assessing health care in critical patient care, and as a source for future researches. 


\section{Nursing \& Healthcare International Journal}

\section{References}

1. Denti IA (2015) Prognosis of disease severity in patients admitted to intensive care units. Perspectiva. Erechim 39(145): 29-39.

2. do Nascimento Calles AC, Moreira ET, Nunes TF, da Silva Santos E (2013) Profile and severity of patients admitted to intensive care units: a literature review. Cadernos de Graduação-Ciências Biológicas e da Saúde Fits 1(2): 45-52.

3. Bezerra GKA (2012) Intensive Care Unit - Profile of Admissions: Regional Hospital of Guarabira, Paraíba, Brazil. R bras ci Saúde 16(4): 491-496.

4. Melo EM (2016) Characterization of patients with infectious diseases hospitalized in an intensive care unit. Revista de enfermagem UFPE on line 10(8): 2942-2947.

5. Carneiro PL, Machado RC, Sant`anna AG (2013) Role of screening priority criteria in critical patient admission. Rev enferm UFPE on line 7(7): 4747-4753.

6. Gomes JC (2015) Criteria for ICU admission and evaluation of the prognosis of elderly patients. Rev. Enfermagem Revista 18(1): 51-57.

7. Oliveira ABF (2010) Factors associated with increased mortality and length of hospital stay in an adult intensive care unit. Rev Bras Ter Intensiva 22(3): 250-256.

8. Favarin SS, Camponogara S (2012) Profile of patients admitted to the adult intensive care unit of a university hospital. Revista Enfermagem UFSM 2(2): 320-329.

9. Duncan BB, Chor D, Aquino EM, Bensenor IM, Mill JG, et al. (2012) Chronic non-communicable diseases in Brazil: priorities for disease management and research. Rev. Saúde Pública 46(1): 126-134.

10. Gomes GB, Gomes VRR (2011) Profile of the elderly hospitalized in the ICU of the interior of São Paulo. Pensamento Plural: Revista Científica do UNIFAE 5(2): 41-46.
11. Freitas ES (2010) Profile and severity of intensive care unit patients: prospective application of the APACHE II score. Rev Latino Am Enferm 18(3): 21-26.

12. Veras R (2008) Population Aging: challenges and innovations needed for the health sector. Revista do Hospital Universitário Pedro Ernesto 7(1): 13-20.

13. Schein LEC, Cesar JA (2010) Profile of elderly admitted to general intensive care units in Rio Grande, RS: results of a demand study. Rev Bras Epidem 13(2): 289-301.

14. Caldeira VMH, Silva JM, Rosa de Oliveira AMR, Rezende S, de Araújo LAG, et al. (2010) Criteria for patient admission to an intensive care unit and related mortality rates. Rev Assoc Med Bras 56(5): 528-34.

15. Araujo TG, Rieder Mde M, Kutchak FM, Franco Filho JW (2013) Readmissions and deaths following ICU discharge: a challenge for intensive care. Rev Bras Ter Intensiva 25(1): 32-38.

16. Brazil (2016) Federal Council of Medicine. 5065 Brazilian municipalities do not have ICU beds, says CFM study.

17. Vieira MS (2011) Geographical and clinical profile of patients admitted to the ICU through the Hospitals Regulation Center. Com. Ciências Saúde 22(3): 201210.

18. Brazil (2012) Guidelines and regulatory norms of research involving human beings. Resolution no. 466, of December 12, 2012. National Health Council, Brasília, DF.

19. Brazil (2003) Law no. 57, dated September 23, 2003 (No. 3,561, of 1997, in the House of Origin). It deals with the Statute of the Elderly and makes other provisions. Official Journal of the Union, September 23.

20. Borges FK (2008) Early hospital rehospitalization: evaluation of an indicator of quality of care. Rev HCPA 28(3): 147-52. 